\title{
Putative Functional Role for the Invariant Aspartate 263 Residue of Rhodospirillum rubrum Rubisco ${ }^{\dagger}$
}

\author{
John R. Liggins ${ }^{\ddagger}$ and Jill E. Gready*,\$ \\ Molecular Plant Physiology Group, Research School of Biological Sciences, and Division of Molecular Bioscience, \\ John Curtin School of Medical Research, Australian National University, Canberra ACT 0200, Australia
}

Received November 22, 2008; Revised Manuscript Received January 8, 2009

\begin{abstract}
Although aspartate residue D263 of Rhodospirillum rubrum Rubisco is close to the active site and invariant in all reported Rubiscos, its possible functional and structural roles in Rubisco activity have not been investigated. We have mutagenised D263 to several selected amino acids (asparagine, alanine, serine, glutamate, and glutamine) to probe possible roles in facilitating proton movements within the active site and maintaining structural positioning of key active-site groups. The mutants have been characterized by kinetic methods and by differential scanning calorimetry (DSC) to examine the effects of the substitutions on the stability of the folded state. We show that D263 is essential for maintaining effective levels of catalysis with the mutations reducing carboxylation variously by up to 100 -fold but having less than $10 \%$ effect on the carboxylase/oxygenase specificity of the catalytic reaction. Removing the charge of the residue 263 side chain significantly strengthens binding of the activating (carbamylating) $\mathrm{CO}_{2}$ molecule. In contrast, a charge on the 263 site has only a small influence on binding of the positively charged $\mathrm{Mg}^{2+}$ ion, suggesting that the local protein structure provides different shielding of the formal charges on the $\mathrm{Mg}^{2+}$ ion and the $\varepsilon$-lysine group of K191. Interestingly, introduction of an internal cavity (D263S and D263A) and insertion of an extra $-\mathrm{CH}_{2}-$ group (D263E and D263Q) have opposite effects on catalysis, the former relatively small and the latter much larger, suggesting that the extra side-chain group induces a specific structural distortion that inhibits formation of the transition state. As the DSC results show that the mutations only slightly increase the kinetic stability of the folded state, we conclude that the rate-limiting (activated) step of unfolding involves substantial unfolding of the structure but not in the region of site 263. In summary, interaction of D263 with H287 of a largely electrostatic nature appears critical for maintaining correct positioning of catalytic groups in the active site. The conservation of D263 can thus be accounted for by its contribution to the maintenance of a finely tuned structure in this region abutting the active site.
\end{abstract}

Ribulose 1,5-bisphosphate carboxylase/oxygenase (Rubisco, EC 4.1.1.39) ${ }^{1}$ facilitates the crucial $\mathrm{CO}_{2}$-fixing step in photosynthesis $(1-5)$ and is the most abundant enzyme on Earth (6). It catalyzes the addition of $\mathrm{CO}_{2}$ and $\mathrm{H}_{2} \mathrm{O}$ to D-ribulose 1,5-bisphosphate (RuBP) to yield two molecules of 3-phospho-D-glycerate (PGA), the first intermediate of the Calvin cycle, but it also catalyzes the oxidation reaction whereby $\mathrm{O}_{2}$ and $\mathrm{H}_{2} \mathrm{O}$ are added to RuBP to yield one molecule of PGA and one molecule of 2-phosphoglycolate. The $\mathrm{CO}_{2}$-fixing (carboxylase) and $\mathrm{O}_{2}$-fixing (oxygenase) reactions are mutually inhibiting; that is, they compete in analogous chemistry at the active site. In vivo, the oxygenase reaction is bioenergetically wasteful, reducing both the

\footnotetext{
${ }^{\dagger}$ This work was supported by an Australian Research Council (ARC) Linkage Grant LP0347461 with Rio Tinto as the Industry Partner.

* To whom correspondence should be addressed. Telephone: +612-6125-8304. Fax: +61-2-6125-2499. E-mail: jill.gready@ anu.edu.au.

\# Molecular Plant Physiology Group.

$\S$ Division of Molecular Bioscience.

${ }^{1}$ Abbreviations: Rubisco, ribulose 1,5-bisphosphate carboxylase/ oxygenase; $R$. rubrum, Rhodospirillum rubrum; $\Delta C_{p}$, difference between the heat capacities of the initial and final states; DSC, differential scanning calorimetry; ITC, isothermal titration calorimetry; $K_{\mathrm{A}}$, association constant of the ligand-protein complex.
}

efficiency of light use in photosynthesis and wasting carbon from the photosynthetic metabolism. Biochemical investigations of Rubisco have the potential to contribute to a major goal of Rubisco research, which is to improve Rubisco's catalytic efficiency and carboxylase/oxygenase specificity factor, $S_{\mathrm{C} / \mathrm{O}}(7)$, and transplant improved Rubiscos into crop plants $(8-10)$.

In higher plants, including spinach (Spinacea oleracea) and tobacco (Nicotiana tabacum), Rubisco is composed of eight large (L) subunits (ca. $53 \mathrm{kDa}$ ) and eight small (S) subunits (ca. $14 \mathrm{kDa}$ ), the holoenzyme thus having the composition $\mathrm{L}_{8} \mathrm{~S}_{8}$ (Form I) (2-4). In some dinoflagellates and prokaryotes, including Rhodospirillum rubrum, Rubisco comprises one large subunit or a dimer of large subunits only $\left(\mathrm{L}_{2}\right)$ (Form II) (11). Other subunit compositions and tertiary structures have been reported for more recently characterized Rubiscos $(4,5)$. There is high structural homology between the subunits of the prokaryote/dinoflagellate Rubisco dimers and the large subunits of the higher plant $\left(\mathrm{L}_{8} \mathrm{~S}_{8}\right)$ Rubisco oligomers; in both cases there is one active site per (large) subunit, with each active site being formed from C-terminal and $\mathrm{N}$-terminal domains of two subunits $(2-4)$. 
Rubisco must be reversibly activated before the catalytic reaction can occur (1). First, a $\mathrm{CO}_{2}$ molecule, which is distinct from the substrate $\mathrm{CO}_{2}$ molecule of the carboxylase reaction, becomes covalently attached as a carbamate to the $\varepsilon$-amino group of an active-site lysyl residue (K191 in the $R$. rubrum sequence which corresponds to K201 in the spinach sequence). This reversible, rate-limiting process is followed by the subsequent rapid binding of an $\mathrm{Mg}^{2+}$ ion which coordinates to one of the carbamino oxygen atoms of the carbamylated K191 and to one of the carboxyl oxygen atoms of both D193 and E194 (corresponding to spinach D203 and E204). The other three coordination positions are occupied by a water molecule and by the O-2 and O-3 atoms of the substrate RuBP. In the absence of RuBP, these three sites are all occupied by water molecules $(4,11,12)$.

These six ligands immediately coordinated to the $\mathrm{Mg}^{2+}$ ion comprise the "first coordination shell", whereas the "second shell" contains mainly positively charged residues (lysines, histidines), which surround and interact with the first shell of coordinated ligands $(12,13)$. Surrounding the second shell is a "polar shell" consisting of several polar and charged, or potentially charged, residues within $10 \AA$ of the $\mathrm{Mg}^{2+}$ ion (13). Aspartate residue D263 in R. rubrum Rubisco (corresponding to D268 in the homologous large subunit of spinach and tobacco Rubiscos) is part of this shell $(12,13)$. The structures of both $R$. rubrum and spinach Rubiscos with relevant first, second, and polar (third) shell residues are shown in Figure 1. Asp residue 263 has been classed as "invariant" as it is completely conserved in all Rubisco sequences known to date (ref (13) and unpublished work). This strong conservation of a group situated close to the active site, but with no obvious role, is intriguing. Definition of its possible role is important both for understanding the complex Rubisco chemistry and for expanding knowledge of non-active-site residues that might be affected by attempts at Rubisco re-engineering.

Duff has suggested that D263 might play a specific catalytic role in enolization or be involved in some other functional step, mediated by an interaction with the side chain of H287 (13) (corresponding to spinach H294). X-ray crystallographic structures show a short distance $(\sim 5 \AA)$ between the side chains of D263 and H287 (Figure 1) which is also found for homologous residues in other Rubisco structures (13-19). The distance between D263 and H287 indicates that any interaction would be indirect, possibly mediated by a water molecule.

Based on the crystallographic structures, another interaction, at the short H-bonding distance of $2.8 \AA$ in spinach Rubisco (see Figure 1B), is suggested between one of the carboxyl oxygen atoms (OD2) of D268 (i.e., D263 in $R$. rubrum) and the carbonyl oxygen of E204 (E194 in $R$. rubrum). Duff postulated a shared proton ("structural hydrogen") between these two residues (13); that is, the Asp is formally protonated. As E204 is one of three residue ligands for the $\mathrm{Mg}^{2+}$ ion, it was suggested that this $\mathrm{H}$ bond might stabilize the enzyme in the closed state (substrate RuBP bound) (13). However, in R. rubrum Rubisco activated with $\mathrm{CO}_{2}$ and $\mathrm{Mg}^{2+}$ in either the free (PDB 2RUS, resolution $2.3 \AA$ (14)) or RuBP complex (PDB 9RUB, resolution 2.6 $\AA$ (15) (Figure 1A), the distances between OD2 of D263 and the carbonyl oxygen of E194 are both at H-bond distance, 2.9 and $3.2 \AA$, respectively. On the other hand, in

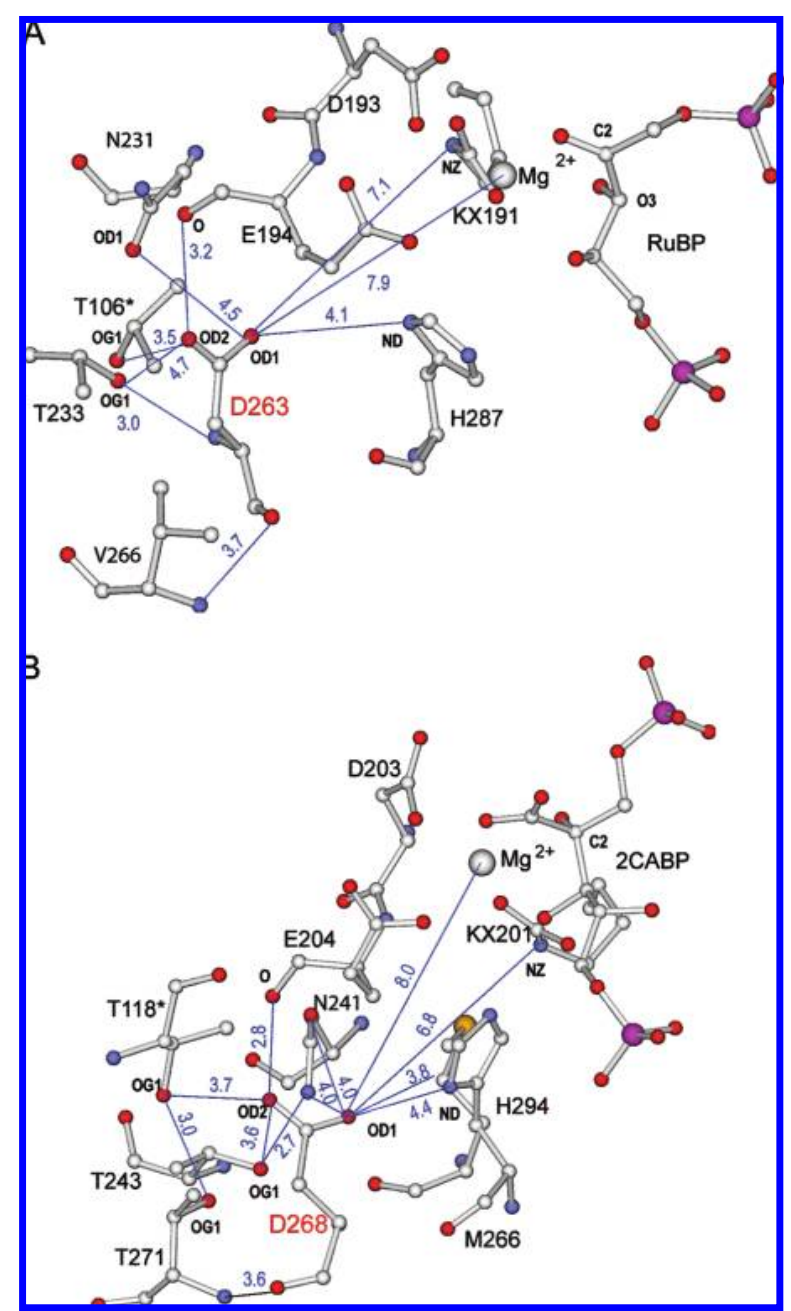

FIGURE 1: Structure of the active site and region immediately surrounding the invariant Asp residue, D263 (R. rubrum) and D268 (spinach). (A) In R. rubrum Rubisco activated with $\mathrm{CO}_{2}$ and $\mathrm{Mg}^{2+}$ and bound RuBP (PDB 9RUB, resolution $2.6 \AA$ (15)). (B) In activated spinach Rubisco with bound $2 \mathrm{CABP}$ (2-carboxyarabinitolbisphosphate, a reaction-intermediate analogue) (PDB 8RUC, resolution $1.6 \AA$ (12)). Key distances from OD1 or OD2 of D263/ D268 to ND of H287/H294, NZ of KX191/KX201 (carbamylated Lys), $\mathrm{Mg}^{2+}$, and O of E194/E204 are shown, together with those of other residues close to D263/D268. Residues marked by an* (T106 and T118) are from the other large subunit of the Rubisco LSU-LSU dimer.

nonactivated R. rubrum Rubisco (PDB 5RUB, resolution 1.7 $\AA$ (17)), the analogous distance is $6.1 \AA$. Hence, the crystallographic evidence for $R$. rubrum Rubisco supports the presence of the $\mathrm{H}$ bond in the activated enzyme but not necessarily only in the (activated) closed state. This is consistent with a role in helping to stabilize the E194- $\mathrm{Mg}^{2+}$ co-ordination in the activated state. However, it should be noted that if the $\mathrm{H}$ bond with E194-O exists, then D263 would need to be protonated; this is not compatible with an "ionic" interaction between D263 and H287 suggested by Duff (13), for which D263 would need to be deprotonated and $\mathrm{H} 287$ protonated.

In this work we have sought to investigate the role of D263 by making several carefully chosen mutations in $R$. rubrum Rubisco:

-First, we made the D263N mutation which makes a specific localized change to the side chain by replacing the carboxylate group with an amide group and leaving the rest of the 
side chain unchanged. We expect that this change would cripple any functional role mediated by the proposed interaction with the side chain of $\mathrm{H} 287$, while preserving any structural role, including the postulated $\mathrm{H}$ bond with E194-O.

-Second, for the D263E mutation we expect that any functional role arising from the interaction of the carboxylate group with the side chain of $\mathrm{H} 287$ would be retained, but that insertion of the extra $-\mathrm{CH}_{2}-$ group will almost certainly strain, and may significantly destabilize, the local structure. -Third, the D263Q mutation combines the effects of the D263N and D263E mutations and would be expected to both cripple the functional role and also distort the local structure. -Fourth, the D263A mutation, involving substitution of a small, hydrophobic side chain for the wild-type Asp side chain, has been included as a control. It is expected that any functional or structural roles of D263 would be abolished, while at the same time producing a sizable internal cavity which might destabilize the enzyme structure.

- Finally, the D263S mutation, involving substitution of a small, hydrophilic side chain for the wild-type Asp side chain, has been included as a second control. We expect properties of D263S similar to those of D263A, except that some of the hydrophilic character of the wild-type side chain is preserved.

We have characterized the catalytic and binding activities of the mutants by kinetic and selected thermodynamic measurements and also evaluated their stabilities by differential scanning calorimetric (DSC) studies. Catalytic constants (rate and Michaelis constants of the substrates $\mathrm{RuBP}$ and $\mathrm{CO}_{2}$ ) and carboxylase/oxygenase specificities have been determined for all mutants. We have also evaluated the effects of the Glu, Asn, and Ser substitutions on the binding constant of the activating (carbamylating) $\mathrm{CO}_{2}$, as well as the effect of the Asn substitution on the binding constant of the activating $\mathrm{Mg}^{2+}$. DSC studies on wild-type Rubisco have previously shown that the thermal unfolding transition is an irreversible process $(20-23)$. This means that Rubisco unfolding is a kinetic, not an equilibrium process. Therefore, DSC can be used to measure the overall enthalpy of unfolding $\left(\Delta H_{\text {cal }}\right)$, the difference in the heat capacities of the folded and unfolded protein molecules $\left(\Delta C_{p ; \text { cal }}\right)$, and the rate constant and the activation parameters of the rate-limiting step of the unfolding transition $\left(k_{\mathrm{u}}, \Delta H_{\mathrm{u}}^{\ddagger}, \Delta S_{\mathrm{u}}^{\ddagger}\right.$, and $\left.\Delta G_{\mathrm{u}}^{\ddagger}\right)$. The dependence, if any, on the rate of Rubisco unfolding for the different amino acid substitutions can be used to assess whether any localized unfolding of the structure at or near the D263 site is crucial to the rate-limiting step of unfolding.

\section{MATERIALS AND METHODS}

Mutagenesis of the Gene for R. rubrum Rubisco. The QuikChange Site-Directed Mutagenesis Kit (Stratagene, La Jolla, CA) was used to introduce modifications to the $r b c \mathrm{M}$ gene cloned in the pET28a $(+)$ based plasmid pRrHis that codes for the $R$. rubrum Rubisco subunit with an N-terminal 6x histidine $\left(\mathrm{His}_{6}\right)$ tag (24). Appropriate primers were used to mutate the aspartate-263 codon (GAC) in $r b c \mathrm{M}$ to asparagine (AAC, D263N), glutamate (GAA, D263E), glutamine (CAG, D263Q), alanine (GCT, D263A), or serine (TCC, D263S).
Purification of His-R. rubrum Rubisco. The variant pRrHis plasmids were transformed into BL21(DE3) E. coli cells and Rubisco expression autoinduced by growing the cells at $22{ }^{\circ} \mathrm{C}$ in Luria-Bertani medium containing $30 \mu \mathrm{g} \mathrm{mL} L^{-1}$ kanamycin supplemented with additional carbon sources $(0.5 \%$ (v/v) glycerol, $2.8 \mathrm{mM}$ glucose, and $5.6 \mathrm{mM} \alpha$-lactose), nutrients, and trace metals (25). After four or five days the cells were harvested by centrifugation $(6000 \mathrm{~g}, 60 \mathrm{~min}$, $4{ }^{\circ} \mathrm{C}$ ) and then suspended in $4 \mathrm{~mL}$ of buffer $(50 \mathrm{mM}$ sodium phosphate $\mathrm{pH} 8,300 \mathrm{mM} \mathrm{NaCl}$, and $20 \mathrm{mM}$ imidazole) per gram of cells and lysozyme was added to a final concentration of $0.1 \mathrm{mg} \mathrm{mL}^{-1}$. After $20 \mathrm{~min}$ of gentle shaking at $4{ }^{\circ} \mathrm{C}$ the cells were fully lysed by passage through a French pressure cell (140 MPa) and then centrifuged at $38000 \mathrm{~g}$ for 20 min at $4{ }^{\circ} \mathrm{C}$. The $\mathrm{His}_{6}$-Rubisco in the supernatant was isolated by immobilized metal affinity chromatography using $\mathrm{Ni}^{2+}$-nitrilotriacetic acid (Ni-NTA) agarose (Qiagen, Victoria, Australia). The purified enzymes were dialysed overnight at $4{ }^{\circ} \mathrm{C}$ against $2 \mathrm{~L}$ of storage buffer $(20 \mathrm{mM}$ Epps $-\mathrm{NaOH}$, $\mathrm{pH} 7.8,50 \mathrm{mM} \mathrm{NaCl}$, and 0.5 mM EDTA), and the Rubisco concentration was determined from absorbance measurements at $280 \mathrm{~nm}$ using an extinction coefficient of $1.2 \mathrm{~cm}^{-1}$ $\left(\mathrm{mg} \mathrm{mL}^{-1}\right)^{-1}(26)$. Glycerol was then added to the enzyme $(15 \%(\mathrm{v} / \mathrm{v}))$ before freezing it in liquid nitrogen and storing it at $-20{ }^{\circ} \mathrm{C}$. The purity of each preparation was checked on a denaturing SDS-PAGE gel and was found to be $>99 \%$ pure.

Quantification of Rubisco Activity and Content. Rubisco activity was determined at $25{ }^{\circ} \mathrm{C}$ using an NADH-coupled spectrophotometric assay for which the carboxylation of each RuBP molecule results in the oxidation of four NADH molecules (27). The assays were performed as described by Emlyn-Jones et al. (28), where the activation of the purified Rubiscos (final concentration $\sim 1 \mu \mathrm{g} \mathrm{mL}^{-1}$ ) using $\mathrm{CO}_{2}(50$ $\mathrm{mM} \mathrm{NaHCO} 3$ ) and $\mathrm{Mg}^{2+}(25 \mathrm{mM} \mathrm{MgCl}$ ) was allowed to proceed for $10 \mathrm{~min}$ before the assays were initiated with 0.25 $\mathrm{mM}$ RuBP that was synthesized according to Kane et al. (29). Rubisco content was accurately measured from the stoichiometic binding of the tight binding inhibitor 2-carboxy-D-arabinitol-1,5-bisphosphate (CABP) as described previously $(24,30)$.

Determination of Michaelis Constants and Binding Constants. Purified enzyme that had been dialysed against $\mathrm{N}_{2-}$ sparged buffer for $24 \mathrm{~h}$ at $4{ }^{\circ} \mathrm{C}$ was used to measure the binding and Michaelis constants using the spectrophotometric assay as described in McNevin et al. (31). The Rubisco samples were preincubated for at least $1 \mathrm{~h}$ at $25^{\circ} \mathrm{C}$ in 50 $\mathrm{mM}$ Epps $-\mathrm{NaOH}$ buffer, $\mathrm{pH} 8$, containing the appropriate concentrations of $\mathrm{NaHCO}_{3}$ and $\mathrm{MgCl}_{2}$ prior to assaying. The assays were covered with paraffin oil to prevent $\mathrm{CO}_{2}$ exchange, and the final $\mathrm{CO}_{2}$ concentrations were calculated using the Henderson-Hasselbach equation using a $\mathrm{p} K_{\mathrm{a}}$ of 6.25 .

To measure the Michaelis constant $\left(K_{\mathrm{M}}\right)$ for RuBP, activated enzyme was added to reactions containing $100 \mathrm{mM}$ Epps- $\mathrm{NaOH}$ pH 8.0, $50 \mathrm{mM} \mathrm{NaHCO}{ }_{3}\left(\sim 835 \mu \mathrm{M} \mathrm{CO}_{2}\right), 25$ $\mathrm{mM} \mathrm{MgCl} 2,1 \mathrm{mM}$ EDTA, and 0-33 $\mu \mathrm{M}$ RuBP. Carboxylation turnover rate was obtained by dividing the Michaelis-Menten extrapolated measure of $V_{\max }$ by the concentration of Rubisco active sites determined by CABP binding (see above). In assays used to measure the $K_{\mathrm{M}}$ for $\mathrm{CO}_{2}$, the enzyme was preactivated in buffer (100 mM Epps- $\mathrm{NaOH}, \mathrm{pH} 8.0,40$ 
$\mathrm{mM} \mathrm{NaHCO} 3,22.5 \mathrm{mM} \mathrm{MgCl}_{2}$, and $1 \mathrm{mM}$ EDTA) and diluted 20-fold into similarly buffered reactions containing 0-15 $\mathrm{mM} \mathrm{NaHCO}$ and $0.5 \mathrm{mM}$ RuBP.

The binding constant for the activating (carbamylating) $\mathrm{CO}_{2}\left(K_{\mathrm{C}}\right)$ was measured by preincubating the enzyme with $0-100 \mathrm{mM}$ (D263N and D263S mutants) or $0.8 \mathrm{mM}$ $\mathrm{NaHCO}_{3}$ and no $\mathrm{MgCl}_{2}$ for several hours before diluting 20fold into assays containing $100 \mathrm{mM}$ Epps $-\mathrm{NaOH}, \mathrm{pH}$ 8.0, $1 \mathrm{mM}$ EDTA, $0.25 \mathrm{mM}$ RuBP, $20 \mathrm{mM} \mathrm{MgCl}_{2}$, and either $12.5 \mathrm{mM}$ (for the D263N and the D263S mutants) or 40 $\mathrm{mM} \mathrm{NaHCO}$. The initial linear increase in activity was extrapolated back to $0 \mathrm{~min}$ to determine the enzyme carbamylation status $\left(V_{\max }\right)$ and plotted against activating $\mathrm{CO}_{2}$ concentration, and $K_{\mathrm{C}}$ determined using a Michaelis - Menten fit. In reactions used to measure the binding constant for $\mathrm{Mg}^{2+}\left(K_{\mathrm{Mg}}\right)$, the Rubisco was incubated in buffer containing $3 \mathrm{mM} \mathrm{NaHCO}$ and $0-20 \mathrm{mM} \mathrm{MgCl} 2$ for $\sim 2 \mathrm{~h}$ before diluting 20-fold into assays containing $100 \mathrm{mM}$ Epps $-\mathrm{NaOH}$, $\mathrm{pH}$ 8.0, $0.25 \mathrm{mM}$ RuBP, $1 \mathrm{mM}$ EDTA, $3 \mathrm{mM} \mathrm{NaHCO}$, and $20 \mathrm{mM} \mathrm{MgCl}$. Initial activity increases were again extrapolated back to zero time to determine the initial proportion of activated (carbamylated- $\mathrm{Mg}^{2+}$-bound) and partially activated (carbamylated but not $\mathrm{Mg}^{2+}$-bound but assumes $\mathrm{Mg}^{2+}$ binding is rapid) Rubisco, and this was plotted as a function of $\mathrm{Mg}^{2+}$ concentration to determine $K_{\mathrm{Mg}}$ and $V_{\max }$ using the following equation:

$$
V=V_{\max }\left(1-\frac{K_{\mathrm{C}} K_{\mathrm{Mg}}}{K_{\mathrm{C}} K_{\mathrm{Mg}}+[\mathrm{C}] K_{\mathrm{Mg}}+[\mathrm{C}][\mathrm{M}]}\right)
$$

where $[\mathrm{C}]$ and $[\mathrm{M}]$ are the concentrations of dissolved $\mathrm{CO}_{2}$ and $\mathrm{Mg}^{2+}$, respectively.

Calculation of the Free Energies. The activation free energy of the catalytic (carboxylase) reaction at $25^{\circ} \mathrm{C}, \Delta G_{\text {cat }}{ }^{\ddagger}$, was calculated from the catalytic constant, $k_{\text {cat }}$, according to the following equation:

$$
\Delta G_{\text {cat }}^{\ddagger}=-R T\left(\ln \left(k_{\text {cat }}\right)-\ln \left(\frac{k T}{h}\right)\right)
$$

where $T$ is the absolute temperature in $\mathrm{K}, R$ is the gas constant, $8.314 \mathrm{~J} \mathrm{~mol}^{-1} \mathrm{~K}^{-1}, k$ is Boltzmann's constant, $h$ is Planck's constant, and the value of $(k T / h)$ at $25^{\circ} \mathrm{C}$ is $6.2 \times$ $10^{12} \mathrm{~s}^{-1}$.

The free energy of binding of the carbamylating (activating) $\mathrm{CO}_{2}$ molecule to Rubisco, $\Delta G_{\mathrm{C}}$, is given by the following equation:

$$
\Delta G_{\mathrm{C}}=-R T \ln \left(K_{\mathrm{C}}\right)
$$

where $K_{\mathrm{C}}$ is the binding constant of the carbamylating (activating) $\mathrm{CO}_{2}$ molecule. The difference between the free energies of binding, $\Delta \Delta G_{\mathrm{C}}$, of the mutant and the wild type is therefore

$$
\Delta \Delta G_{\mathrm{C}}=-R T\left(\ln \left(K_{\mathrm{C} ; \mathrm{wt}}\right)-\ln \left(K_{\mathrm{C} ; \mathrm{mut}}\right)\right)
$$

where $K_{\mathrm{C} ; w \mathrm{t}}$ and $K_{\mathrm{C} ; \mathrm{mut}}$ are the measured $K_{\mathrm{C}}$ values for the wild-type and mutant Rubiscos, respectively.

Determination of the Carboxylase/Oxygenase Specificity Using ${ }^{3} H-R u B P$. The carboxylase/oxygenase specificity, $S_{\mathrm{C} / \mathrm{O}}$, was determined using the method of Kane et al. (7) using ${ }^{3} \mathrm{H}-\mathrm{RuBP}$ in reactions equilibrated with an atmosphere containing $5000 \mathrm{ppm} \mathrm{CO} 2$ in $\mathrm{O}_{2}$ which was controlled using three Wösthoff precision gas-mixing pumps.

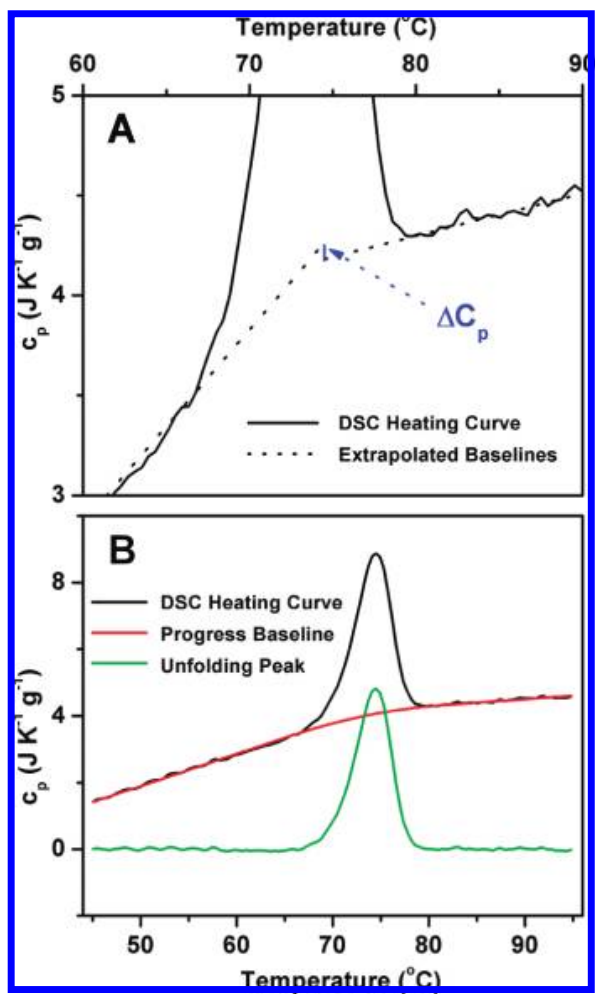

FIGURE 2: Differential scanning calorimetric (DSC) unfolding curve of wild-type (D263) R. rubrum Rubisco in $20 \%$ glycerol. The concentration of Rubisco dimer was $1.13 \mu \mathrm{M}$. The DSC heating curve, obtained as described in the Materials and Methods, is shown in (A) and (B). The extrapolated low and high temperature baselines, showing $\Delta C_{p}$ at the apparent unfolding temperature, obtained as described in the Materials and Methods, are shown in (A). The DSC unfolding peak, obtained by subtracting the progress baseline from the DSC heating curve, as described in the Materials and Methods, is shown in (B).

Differential Scanning Calorimetry (DSC). DSC was performed on a VP-DSC calorimeter from MicroCal Corporation (Northampton, MA) with a cell volume of $0.514 \mathrm{~mL}$ and the buffer $20 \mathrm{mM}$ Hepes $-\mathrm{NaOH}, 50 \mathrm{mM} \mathrm{NaCl}, 0.5 \mathrm{mM}$ EDTA, 20\% glycerol, pH 7.6. Upward scans were obtained with buffer in both the sample and reference cells, and also with protein solution in the sample cell and buffer in the reference cell. The DSC heating curve was then obtained by subtracting the buffer/buffer scan from the protein/buffer scan, using the DSC in Origin program supplied with the VP-DSC. A correction was made for the heat capacity of the small amount of buffer displaced by the protein in solution $(32,33)$. The difference between the heat capacities of folded and unfolded Rubisco, $\Delta C_{p \text {;cal }}$, was obtained by subtracting the heat capacity of the extrapolated low temperature baseline (heat capacity as a function of temperature of the folded protein) from the heat capacity of the extrapolated high temperature baseline (heat capacity as a function of temperature of the unfolded protein) using DSC in Origin (Figure 2A). Extrapolations of the low and high temperature baselines were merged using the Progress Baseline function in DSC in Origin. The progress baseline was then subtracted from the DSC heating curve to obtain the DSC unfolding peak shown in Figure 2B. Values of the apparent temperature of unfolding, $T_{\mathrm{u}}$, were obtained using DSC in Origin. The calorimetric enthalpy of unfolding of the Rubisco monomer, $\Delta H_{\text {cal }}$ (monomer), was obtained by measuring the area under the calorimetric unfolding peak 
Table 1: Catalytic Parameters of the R. rubrum Rubisco D263 Mutants for the Carboxylation Reaction

\begin{tabular}{|c|c|c|c|c|c|c|c|c|c|c|c|c|}
\hline mutant & $\begin{array}{l}k_{\text {cat }}{ }^{a} \\
\left(\mathrm{~s}^{-1}\right)\end{array}$ & $\begin{array}{l}k_{\mathrm{cat}}^{a} \\
(\%)\end{array}$ & $\begin{array}{c}\Delta G_{\mathrm{cat}}{ }^{\ddagger a} \\
\left(\mathrm{~kJ} \mathrm{~mol}^{-1}\right)\end{array}$ & $\begin{array}{l}\Delta \Delta G_{\mathrm{cat}^{+} b} \\
\left(\mathrm{~kJ} \mathrm{~mol}^{-1}\right)\end{array}$ & $S_{\mathrm{C} / \mathrm{O}^{a}}$ & $\begin{array}{c}K_{\mathrm{M}}{ }^{a} \\
(\mathrm{RuBP}) \\
(\mu \mathrm{M})\end{array}$ & $\begin{array}{c}k_{\mathrm{cal}} / K_{\mathrm{M}}{ }^{c} \\
(\mathrm{RuBP}) \\
\left(\mu \mathrm{M}^{-1} \mathrm{~s}^{-1}\right)\end{array}$ & $\begin{array}{c}K_{\mathrm{M}}{ }^{a} \\
\left(\mathrm{CO}_{2}\right) \\
(\mu \mathrm{M})\end{array}$ & $\begin{array}{c}k_{\mathrm{cat}} / K_{\mathrm{M}}{ }^{c} \\
\left(\mathrm{CO}_{2}\right) \\
\left(\mu \mathrm{M}^{-1} \mathrm{~s}^{-1}\right)\end{array}$ & $\begin{array}{c}K_{\mathrm{C}}{ }^{a} \\
(\mathrm{mM})\end{array}$ & $\underset{\left(\mathrm{kJ} \mathrm{mol}^{-1}\right)}{\Delta \Delta G_{\mathrm{C}}{ }^{d}}$ & $\begin{array}{l}K_{\mathrm{Mg}}{ }^{a} \\
(\mu \mathrm{M})\end{array}$ \\
\hline wild type (D263) & 6.28 & 100 & 68.5 & 0 & 9.2 & 12.8 & 0.49 & 446 & 0.014 & 7.4 & 0 & 68 \\
\hline $\mathrm{D} 263 \mathrm{~N}$ & 0.82 & 13 & 73.5 & 5.0 & 8.8 & 9.8 & 0.084 & 26 & 0.032 & 0.20 & -9.0 & 162 \\
\hline D263Q & 0.20 & 3.2 & 77.0 & 8.5 & 9.3 & 1.3 & 0.16 & 14 & 0.015 & & & \\
\hline $\mathrm{D} 263 \mathrm{~S}$ & 0.46 & 7.3 & 75.0 & 6.5 & 10.1 & 8.9 & 0.052 & 9 & 0.049 & 0.12 & -10.2 & \\
\hline D263A & 0.81 & 13 & 73.5 & 5.0 & 9.2 & 5.0 & 0.16 & 18 & 0.044 & & & \\
\hline
\end{tabular}

${ }^{a} k_{\text {cat }}, \Delta G_{\text {cat }}{ }^{*}, S_{\mathrm{C} / \mathrm{O}}, K_{\mathrm{M}}(\mathrm{RuBP}), K_{\mathrm{M}}\left(\mathrm{CO}_{2}\right), K_{\mathrm{C}}, K_{\mathrm{Mg}}$ : rate constant, activation free energy of the catalytic (carboxylase) reaction, carboxylase/oxygenase specificity, Michaelis constants for $\mathrm{RuBP}$ and $\mathrm{CO}_{2}$, and binding constants of carbamylating (activating) $\mathrm{CO}_{2}$ and activating $\mathrm{Mg}^{2+}$ ion, all at $25{ }^{\circ} \mathrm{C}$ obtained as described in the Materials and Methods. ${ }^{b} \Delta \Delta G_{\text {cat }}{ }^{\ddagger}$ : difference between activation free energies of carboxylase reaction of mutant and wild type. ${ }^{c} k_{\text {cat }} / K_{\mathrm{M}}(\mathrm{RuBP}), k_{\mathrm{cat}} / K_{\mathrm{M}}\left(\mathrm{CO}_{2}\right)$ : catalytic efficiency constants for RuBP and $\mathrm{CO}_{2}$ at $25{ }^{\circ} \mathrm{C} .{ }^{d} \Delta \Delta G_{\mathrm{C}}$ : difference between free energies of binding of carbamylating (activating) $\mathrm{CO}_{2}$ to mutant and wild type, calculated as described in the Materials and Methods.

with DSC in Origin. The calorimetric enthalpy of unfolding of the Rubisco dimer, $\Delta H_{\text {cal }}$ (dimer), was obtained by multiplying $\Delta H_{\text {cal }}$ (monomer) by 2 . The activation entropy of unfolding, $\Delta S_{\mathrm{u}^{*}}$, and the activation enthalpy of unfolding, $\Delta H_{\mathrm{u}}{ }^{\ddagger}$, both at $T_{\mathrm{u}}$, and the kinetic constant of unfolding, $k_{\mathrm{u}}$, as a function of temperature were obtained by fitting the calorimetric unfolding peak to the equations (derived in the Supporting Information):

$$
C_{P}=\Delta H_{\text {cal }} \frac{\mathrm{d} n}{\mathrm{~d} T}=\frac{-k_{\mathrm{u}} n \Delta H_{\mathrm{cal}}}{q}
$$

and

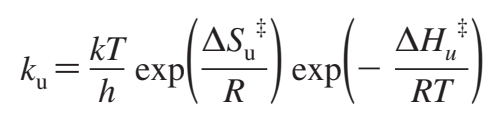

where $T$ is the absolute temperature, $q$ is the heating rate in $\mathrm{K} \mathrm{s}^{-1}, n$ is the fraction of molecules in the folded state as a function of $T$ and $k, h$, and $R$ are as defined previously. The assumption was made that, over the temperature range of the unfolding transition, these parameters do not vary significantly. The activation free energy of unfolding, $\Delta G_{\mathrm{u}}^{\ddagger}$, as a function of temperature over the temperature range of the unfolding transition was then calculated from the following equation:

$$
\Delta G_{\mathrm{u}}^{\ddagger}=\Delta H_{\mathrm{u}}^{\ddagger}-T \Delta S_{\mathrm{u}}^{\ddagger}
$$

\section{RESULTS}

Effects of Substitutions on Catalytic Activity and Specificity. All substitutions at the D263 site reduce the catalytic activity of Rubisco greatly, as shown in Table 1 by the catalytic rate constants, $k_{\text {cat }}$, and the activation free energies for the carboxylase reaction, $\Delta G_{\text {cat }}$. The catalytic rates are reduced by $85-97 \%$, with the least active mutant being D263Q. The control substitutions, D263A and D263S, which effectively replace the entire side chain by small hydrophobic and hydrophilic groups, retain some catalytic activity (13 and $7 \%$, respectively). However, the effect on the carboxylase/oxygenase specificity, $S_{\mathrm{C} / \mathrm{O}}$ (Table 1), is relatively small $(<10 \%)$; that is, the kinetic efficiency of the oxygenase reaction is affected similarly to that of the carboxylase reaction.

Effects of Substitutions on the Michaelis Constant, $K_{M}$, of Substrate RuBP. Values of $K_{\mathrm{M}}$ for RuBP of the wild-type and mutant Rubiscos in Table 1 show reductions for all substitutions very roughly in the same order as the catalytic rates are affected; i.e., wild-type D263 shows both the highest values of $K_{\mathrm{M}}$ and $k_{\text {cat }}$ while D263Q has the lowest. The pattern fits the case in which $k_{\text {cat }}$ is either higher or of the same order of magnitude as the rate constant for the dissociation of an enzyme/substrate complex back to its free components (34).

Effects of Substitutions on the Michaelis Constant, $K_{M}$, of Substrate $\mathrm{CO}_{2}$. Values of $K_{\mathrm{M}}$ for substrate $\mathrm{CO}_{2}$ for wildtype and mutant Rubiscos in Table 1 again show reductions for substitutions very roughly in the same order as the catalytic rate is affected. However, a secondary effect is apparent by comparing the data for the Glu (D263E) and Asn (D263N) mutants with that of the wild type: although the mutants have approximately the same values of $k_{\text {cat }}$, D263E has a significantly higher value of $K_{\mathrm{M}}$ than does D263N. It appears that the two enzymes with a carboxyl residue at position 263 have higher $K_{\mathrm{M}}$ values than mutants with uncharged residues (either large or small) at this site.

Effects of Substitutions on Binding Constants of Activating (Carbamylating) $\mathrm{CO}_{2}, \mathrm{~K}_{\mathrm{C}}$, and Activating $\mathrm{Mg}^{2+}$ Ion, $\mathrm{K}_{\mathrm{Mg}}$. Values of $K_{\mathrm{C}}$ and $K_{\mathrm{Mg}}$ for activating $\mathrm{CO}_{2}$ and $\mathrm{Mg}^{2+}$ for wildtype and selected mutant Rubiscos are given in Table 1. Strikingly, the type of substitution considerably affects the binding constant, $K_{\mathrm{C}}$, of the activating (carbamylating) $\mathrm{CO}_{2}$ molecule. Both proteins with carboxyl side chains at site 263 (wild-type and mutant D263E) have considerably higher values than those for D263N and D263S which, respectively, have large and small polar residues at the site. Thus, the presence or absence of a negative charge at the residue 263 site appears important for the strength of binding of the carbamylating $\mathrm{CO}_{2}$ molecule. Values of $K_{\mathrm{Mg}}$ for two representative proteins, wild-type and mutant D263N, differ only by a factor of 2 and are comparable with other values reported in the literature for wild-type $R$. rubrum Rubisco (35).

Heat-Induced Unfolding of Rubisco Observed by Differential Scanning Calorimetry (DSC). The temperatureinduced unfolding of $R$. rubrum Rubisco is reflected by a single DSC peak which is completely irreversible (Figure 2). Therefore, the unfolding transition under these conditions is an entirely kinetic process, as evidenced by the two principal features of the DSC unfolding peak: (i) it is completely irreversible, and (ii) the apparent temperature of unfolding $\left(T_{\mathrm{u}}\right)$ is dependent on the scan rate (Figure 3 ). This result is similar to a previous report for tobacco Rubisco (22).

The rate constant $\left(k_{\mathrm{u}}\right)$ and the activation parameters $\left(\Delta H_{\mathrm{u}}\right.$, $\Delta S_{\mathrm{u}}^{\ddagger}$, and $\left.\Delta G_{\mathrm{u}^{\ddagger}}^{\ddagger}\right)$ of the rate-limiting step of unfolding, and 


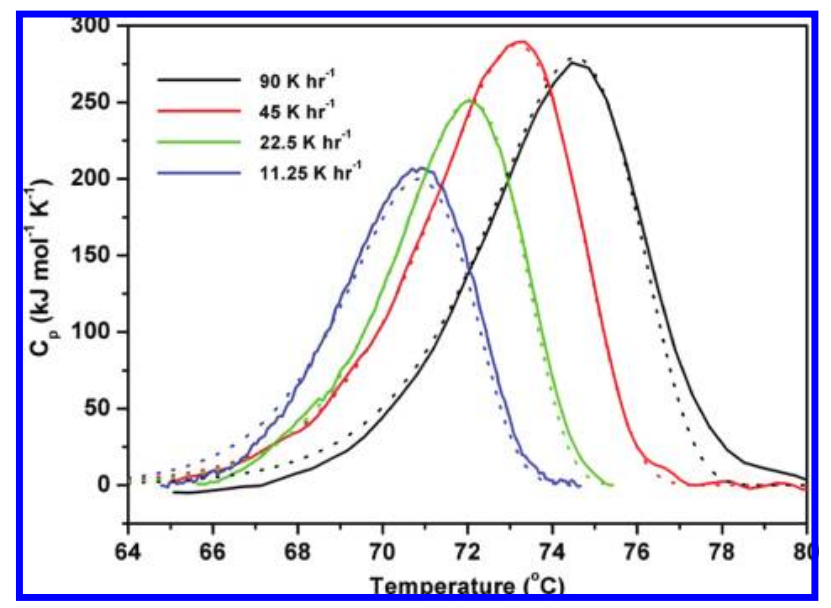

FIGURE 3: Differential scanning calorimetric (DSC) unfolding curves at variable scan rates of wild-type (D263) $R$. rubrum Rubisco in $20 \%$ glycerol. The concentration of Rubisco dimer was $1.13 \mu \mathrm{M}$. The DSC unfolding peaks at four different scan rates were obtained as described in the Materials and Methods. The solid lines represent the experimental data. The dotted lines represent fits of eq 5 to the data, as described in the Materials and Methods.

also the total enthalpy of unfolding $\left(\Delta H_{\text {cal }}\right)$, and the change in the heat capacity of unfolding $\left(\Delta \mathrm{C}_{\mathrm{p} \text {; cal }}\right)$ were obtained by analyzing these DSC transitions: they are presented in Table 2.

DSC scans of the heat-induced unfolding of all Rubisco 263-site mutants are similar in shape to that of the wild type (Figure 4): the only real differences are the small differences, $\Delta T_{\mathrm{u}}$, in the apparent temperatures of unfolding (Table 3). Together with the fact that they all display some catalytic activity (Table 1) and migrate similarly on a native (nondenaturing) gel (data not shown), this strongly suggests that all mutant Rubiscos exist as folded conformations similar to that of the wild type.

The small, negative value of $\Delta C_{p \text {; cal }}$ (Figure 2A, Table 2) is noteworthy. Although large positive values of $\Delta C_{p \text {;cal }}$ have been obtained for many small globular proteins (36), $R$. rubrum Rubisco is a large molecular weight protein dimer of approximately $106 \mathrm{kDa}$ which denatures irreversibly. At temperatures above the unfolding temperature, such large proteins can undergo processes such as intermolecular aggregation. Moreover, regions of the polypeptide chains of large denatured proteins may loosely associate in semicompact structures. Such effects can result in contributions to $\Delta C_{p ; \text { cal }}$ which are not present in many small globular proteins which denature reversibly.

All of the site 263 substitutions reduce the kinetic rate for unfolding of Rubisco, i.e., stabilize the protein, but only by a small amount (Figure 4, Table 3).

\section{DISCUSSION}

Expected Effects from the Mutational Changes. As summarized in the introductory section, the five substitutions made at site 263 can be expected to result in various types of structural change of the enzyme that might lead to reduction of catalytic activity either directly or indirectly through destabilization of the folded conformation of the protein. Changes in H-bond networks, as shown in Figure 1 for the wild type, including for an electrostatic interaction if the side chains of either D263 or H287 or both were ionized, can be expected to have a variable energetic cost $(37,38)$. The creation of an internal cavity by the replacement of the large side chain of D263 by a small side chain (A or S) could be predicted to result in a destabilization of $6-12 \mathrm{~kJ} \mathrm{~mol}^{-1}$ (39). Strain (and possible disruption) on the structure from insertion of an extra $-\mathrm{CH}_{2}-$ group (in the side chains of $\mathrm{E}$ and Q) could likely result in a destabilization of approximately $4 \mathrm{~kJ} \mathrm{~mol}^{-1}$ : see, for example, the destabilization caused by the insertion of an extra hydroxyl ( $-\mathrm{OH}$ group) in the interior of yeast cytochrome $c$ from the F82Y substitution (40). These general expectations are subject to the usual caveat that the substitutions have no significant effects (structural, electrostatic, etc.) other than the obvious ones: it is well-known that local disruptions to protein structure from these types of mutations can have surprising long-range effects which are not readily predicted.

The effects on both catalytic activity and kinetics of unfolding of Rubisco obtained from the experimental data are presented in Table 4. These have been organized to show the energetic contributions which result from the combinations of substitutions at site 263.

Interactions of the D263 Site with Nearby Residues and the Active Site. We will discuss the mutation results with reference to the structures and interaction networks shown in Figure 1 for complexes of $R$. rubrum and spinach Rubisco.

Although many crystal structures are available for spinach Rubisco in various complexes representing different steps of the reaction pathway $(4,41)$, only four structures are available for wild-type $R$. rubrum Rubisco. Apart from one of these structures (PDB 1RUS), which is for Rubisco complexed with its product, 3-phospho-D-glycerate and which is therefore not considered relevant to this investigation, these are for activated Rubisco in ligand-free (PDB 2RUS, resolution $2.3 \AA$ (14)) and RuBP-bound (PDB 9RUB, resolution $2.6 \AA$ (15); Figure 1A) forms and for nonactivated enzyme (PDB 5RUB, resolution $1.7 \AA$ (17)). Only the first two show short distances between D263 (OD2) and E194 (carbonyl O) of 2.9 and $3.2 \AA$, respectively. We note that the 9RUB structure was determined from a catalytically inactive substrate complex obtained by activation and RuBP binding after crystallization; it may have structural artifacts as evidenced, for example, by distorted positioning and distances of the $\mathrm{Mg}^{2+}$ ligands. Also as noted in the introduction, the corresponding distance (D268-OD2 to E204-O) is $2.8 \AA$ for the structure of activated spinach Rubisco complexed with the inhibitor 2-carboxyarabinitol bisphosphate (CABP) (PDB 8RUC, resolution $1.6 \AA$ (12); Figure $1 \mathrm{~B})$. This structure is regarded as mimicking a later stage of the reaction (the carboxylated intermediate 2-carboxy-3-ketoarabinitol-bisphosphate (2C3KABP)) (12). Although there is no comparable complex structure for $R$. rubrum Rubisco, for purposes of the current discussion this does not matter.

We also point out that the D263 backbone and OD1 and OD2 atoms are involved in several other H-bond networks or short interactions with neighboring residues, including with $\mathrm{N}$-terminal domain residues of the other large subunit of the Rubisco dimer (labeled by * in Figure 1A,B).

Effects from Replacement of the Carboxylate Group. Both $\mathrm{D} \rightarrow \mathrm{N}$ and $\mathrm{E} \rightarrow \mathrm{Q}$ substitutions replace a carboxylate group by an amide group, but the side chains of both the initial and final residues of the $\mathrm{E} \rightarrow \mathrm{Q}$ substitution (Table 4) have 
Table 2: Dependence on the Scan Rate of the Kinetic and Calorimetric Parameters of Unfolding of Wild-Type (D263) $R$. rubrum Rubisco at $74.5^{\circ} \mathrm{C}$

\begin{tabular}{|c|c|c|c|c|c|c|c|c|c|c|c|c|}
\hline $\begin{array}{c}\text { scan rate } \\
\left(\mathrm{K} \mathrm{h}^{-1}\right)\end{array}$ & $\begin{array}{c}T_{\mathrm{u}}^{a} \\
\left({ }^{\circ} \mathrm{C}\right) \\
\end{array}$ & $\begin{array}{c}\Delta T_{\mathrm{u}}{ }^{b} \\
(\mathrm{~K})\end{array}$ & $\begin{array}{c}k_{\mathrm{u}}^{c} \\
\left(T_{\mathrm{u}}\right) \\
\left(\mathrm{s}^{-1} \times\right. \\
1000) \\
\end{array}$ & $\begin{array}{c}k_{\mathrm{u}}^{c} \\
\left(74.5^{\circ} \mathrm{C}\right) \\
\left(\mathrm{s}^{-1} \times\right. \\
1000) \\
\end{array}$ & $\begin{array}{c}\Delta G_{\mathrm{u}}^{\ddagger c} \\
\left(74.5^{\circ} \mathrm{C}\right) \\
\left(\mathrm{kJ} \mathrm{mol}^{-1}\right) \\
\end{array}$ & $\begin{array}{c}\Delta S_{\mathrm{u}}{ }^{\ddagger} d \\
\left(74.5^{\circ} \mathrm{C}\right) \\
\left(\mathrm{kJ} \mathrm{mol}{ }^{-1} \mathrm{~K}^{-1}\right)\end{array}$ & $\begin{array}{c}\Delta H_{\mathrm{u}}^{\ddagger}{ }^{\ddagger} \\
\left(74.5^{\circ} \mathrm{C}\right) \\
\left(\mathrm{kJ} \mathrm{mol}{ }^{-1}\right)\end{array}$ & $\begin{array}{c}\Delta C_{p ; \text { cal }}{ }^{a} \\
\left(74.5^{\circ} \mathrm{C}\right) \\
\left(\mathrm{mJ} \mathrm{K}^{-1} \mathrm{~g}^{-1}\right)\end{array}$ & $\begin{array}{c}\Delta H_{\text {cal }}{ }^{a} \\
(\text { monomer) } \\
\left(\mathrm{kJ} \mathrm{mol}^{-1}\right)\end{array}$ & $\begin{array}{c}\Delta H_{\mathrm{u}}^{\ddagger} / \Delta H_{\text {cal }}{ }^{e} \\
\left(\begin{array}{c}\text { monomer) } \\
(\%)\end{array}\right. \\
\text { (\%) }\end{array}$ & $\begin{array}{c}\Delta H_{\text {cal }}{ }^{a} \\
(\text { dimer }) \\
\left(\mathrm{kJ} \mathrm{mol}^{-1}\right)\end{array}$ & $\begin{array}{c}\Delta H_{\mathrm{u}}^{\ddagger} / \Delta H_{\text {cal }}{ }^{e} \\
(\text { dimer }) \\
(\%)\end{array}$ \\
\hline 45 & 73.4 & -1.1 & 8.1 & 15.3 & 98 & 1.4 & 570 & & & & & \\
\hline 22.5 & 72.1 & -2.4 & 4.4 & 22.5 & 97 & 1.7 & 680 & & & & & \\
\hline 11.25 & 70.9 & -3.6 & 2.2 & 23.9 & 96 & 1.6 & 660 & & & & & \\
\hline
\end{tabular}

${ }^{a} T_{\mathrm{u}}, \Delta C_{p ; \text { cal }}, \Delta H_{\text {cal }}$ (monomer), $\Delta H_{\text {cal }}$ (dimer): apparent temperature of unfolding, the difference between the heat capacities of folded and unfolded Rubisco at $T_{\mathrm{u}}\left(74.5^{\circ} \mathrm{C}\right)$, and the calorimetric enthalpies of unfolding of the Rubisco monomer and dimer at $74.5^{\circ} \mathrm{C}$, obtained as described in the Materials and Methods. ${ }^{b} \Delta T_{\mathrm{u}}$ : difference between $T_{\mathrm{u}}$ at a particular scan rate and $T_{\mathrm{u}}$ at a scan rate of $90 \mathrm{~K} \mathrm{~h}^{-1}$. ${ }^{c} \Delta G_{\mathrm{u}}{ }^{\circ}, k_{\mathrm{u}}\left(T_{\mathrm{u}}\right), k_{\mathrm{u}}\left(74.5^{\circ} \mathrm{C}\right)$ : activation free energy of unfolding at $74.5^{\circ} \mathrm{C}$, the kinetic constant of unfolding at $T_{\mathrm{u}}$, and the kinetic constant of unfolding at $74.5^{\circ} \mathrm{C}$, calculated from $\Delta H_{\mathrm{u}}{ }^{\ddagger}$ and $\Delta S_{\mathrm{u}}^{\ddagger}$, as described in the Materials and Methods. ${ }^{d} \Delta S_{\mathrm{u}}{ }^{\ddagger}, \Delta H_{\mathrm{u}}^{\ddagger}$ : activation entropy and activation enthalpy of unfolding at $74.5^{\circ} \mathrm{C}$, obtained as described in the Materials and Methods. ${ }^{e} \Delta H_{\mathrm{u}}{ }^{\ddagger} / \Delta H_{\text {cal }}$ (monomer), $\Delta H_{\mathrm{u}}{ }^{\ddagger} / \Delta H_{\text {cal }}$ (dimer): activation enthalpy of unfolding as a percentage of the calorimetric enthalpy of unfolding of the Rubisco monomer and as a percentage of the calorimetric enthalpy of unfolding of the Rubisco dimer at $T_{\mathrm{u}}\left(74.5{ }^{\circ} \mathrm{C}\right)$.

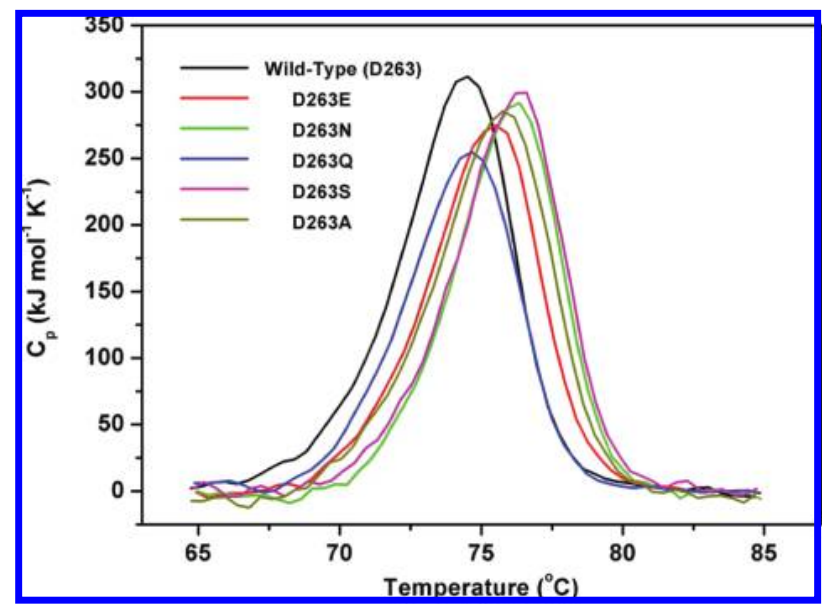

FIGURE 4: Differential scanning calorimetric (DSC) unfolding curves of site 263 mutants of $R$. rubrum Rubisco in $20 \%$ glycerol. The scan rate was $90 \mathrm{~K} \mathrm{~h}^{-1}$. The concentration of Rubisco dimer was $1.13 \mu \mathrm{M}$. The DSC unfolding peaks were obtained as described in the Materials and Methods.

an extra $-\mathrm{CH}_{2}-$ group which could be expected to induce some structural distortion. However, the results show that both the $\mathrm{D} \rightarrow \mathrm{N}$ and $\mathrm{E} \rightarrow \mathrm{Q}$ substitutions have similar effects on the catalytic rate, with values of $\Delta \Delta G_{\text {cat }}$ of 5.05 and 3.85 $\mathrm{kJ} \mathrm{mol}^{-1}$, respectively. This suggests that any intramolecular interactions made by the carboxylate side chain of D263 in the wild-type protein, either with the side chain of H287 or with any other residue, and serving specific functional roles, are retained in the $\mathrm{D} 263 \mathrm{E}$ protein; i.e., any distortion of the carboxylate-group interactions due to insertion of the extra $-\mathrm{CH}_{2}-$ group is relatively small.

Hence, the results suggest that the functional role of the carboxylate side chain is still intact in the D263E protein. The contribution to the catalytic rate made by carboxylate group interactions can be estimated as $4.5 \mathrm{~kJ} \mathrm{~mol}^{-1}$, i.e. the average of the values of $\Delta \Delta G_{\text {cat }}{ }^{*}$ for the $\mathrm{D} \rightarrow \mathrm{N}$ and $\mathrm{E} \rightarrow \mathrm{Q}$ substitutions. As reviewed in the introduction, Duff suggested that the D263 carboxylate group might be involved in a functional step, specifically enolization, mediated by an ionicbond interaction with the side chain of H287 (13). However, although the distance between the side chains of D263 and $\mathrm{H} 287$ is relatively short at $\sim 5 \AA$ for $R$. rubrum and homologous residues in other Rubisco structures (13-19) (Figure 1), such an interaction would necessarily be indirect, possibly mediated by a water molecule. Although both the distance and free-energy contribution $\left(4.5 \mathrm{~kJ} \mathrm{~mol}^{-1}\right)$ are still within the ranges of those classed as ionic interactions, which have been observed to extend over considerable distances (38), the question is whether one or both partners is charged.

The results of our recent computational simulation of the entire Rubisco carboxylase pathway (42) indicate that H287 is protonated on the ND atom (see Figure 1) at all steps but that it is also protonated on the NE atom (i.e., it is positively charged) from the transition state for the $\mathrm{CO}_{2}$ addition onward except for the gem diolate intermediate between the hydration and C2-C3 bond-scission steps (Scheme 2 in ref (42)). The NE atom is not protonated at the enediolate stage after enolization. As discussed below on the binding of the carbamylating $\mathrm{CO}_{2}$ molecule, our results do not support Duff's speculation of a neutral carboxylic acid group for D263 (13), so the functional interaction between D263 and $\mathrm{H} 287$ is likely to be partially or fully ionic depending on the stage of the reaction and mediated by a water molecule.

Effects from Insertion of the $-\mathrm{CH}_{2}-$ Group. Both $\mathrm{D} \rightarrow \mathrm{E}$ and $\mathrm{N} \rightarrow \mathrm{Q}$ substitutions insert a $-\mathrm{CH}_{2}-$ group into the side chain at site 263 . The results in Table 4 show that these substitutions have similar effects on the catalytic activity, with $\Delta \Delta G_{\text {cat }}{ }^{\ddagger}$ values of 4.71 and $3.51 \mathrm{~kJ} \mathrm{~mol}^{-1}$, respectively. The average effect may thus be estimated as $4.1 \mathrm{~kJ} \mathrm{~mol}^{-1}$. A local structural distortion of this type could be expected to result in a destabilization of this order. Overall, the result suggests that insertion of the $-\mathrm{CH}_{2}-$ group at this particular site (263) causes strain in a localized region of structure which is essential for promotion of the transition state of the rate-limiting step of catalysis (which has been assumed to be the same as the wild type for all mutants).

Additive Effects from Replacement of the Carboxylate Group and Insertion of the $-\mathrm{CH}_{2}-$ Group. The effects of both replacing the carboxylate group by an amide group and extending the side chain by a $-\mathrm{CH}_{2}-$ group, which together constitute the $\mathrm{D} \rightarrow \mathrm{Q}$ substitution, are strictly additive in that a value for $\Delta \Delta G_{\text {cat }}{ }^{\ddagger}$ of $8.56 \mathrm{~kJ} \mathrm{~mol}^{-1}$ can be deduced.

As shown in Figure 1, the most likely mechanism for both types of mutational change to affect catalysis is via $\mathrm{H} 287$ or E194. Our recent computational simulation study has suggested a much greater role for $\mathrm{H} 287$ in the overall reaction sequence than previously suggested (1), with multiple active roles in the carboxylation, hydration, and bond-scission steps through proton shuttling between its ND atom and the O3 atom of substrate and intermediates (42). Although no catalytic role for E194 in the carboxylase mechanism had been proposed previously, our computational mechanism suggests an active role in the hydration step in which it 
Table 3: Kinetic Parameters of Unfolding of the Site 263 Mutants of R. rubrum Rubisco

\begin{tabular}{|c|c|c|c|c|c|c|c|c|}
\hline mutant & $\begin{array}{l}T_{\mathrm{u}}^{a} \\
\left({ }^{\circ} \mathrm{C}\right)\end{array}$ & $\begin{array}{l}\Delta T_{\mathrm{u}}^{b} \\
(\mathrm{~K})\end{array}$ & $\begin{array}{c}k_{\mathrm{u}}{ }^{c} \\
\left(\mathrm{~s}^{-1} \times 1000\right)\end{array}$ & $\begin{array}{l}k_{\mathrm{u}}{ }^{d} \\
(\%)\end{array}$ & $\begin{array}{c}\Delta G_{\mathrm{u}}^{\ddagger c} \\
\left(\mathrm{~kJ} \mathrm{~mol}^{-1}\right)\end{array}$ & $\begin{array}{c}\Delta \Delta G_{\mathrm{u}}^{\ddagger e} \\
\left(\mathrm{~kJ} \mathrm{~mol}^{-1}\right)\end{array}$ & $\begin{array}{c}\Delta H_{\mathrm{u}}^{\ddagger f} \\
\left(\mathrm{~kJ} \mathrm{~mol}^{-1}\right)\end{array}$ & $\begin{array}{c}\Delta S_{\mathrm{u}}^{\ddagger f} \\
\left(\mathrm{~kJ} \mathrm{~mol}{ }^{-1} \mathrm{~K}^{-1}\right)\end{array}$ \\
\hline wild type (D263) & 74.5 & 0 & 13 & 100 & 98.1 & 0 & 525 & 1.2 \\
\hline $\mathrm{D} 263 \mathrm{E}$ & 75.5 & 1.0 & 8 & 62 & 99.5 & 1.4 & 540 & 1.3 \\
\hline D263Q & 74.7 & 0.2 & 12 & 94 & 98.3 & 0.2 & 535 & 1.3 \\
\hline D263S & 76.3 & 1.8 & 5 & 38 & 100.9 & 2.8 & 555 & 1.3 \\
\hline D263A & 75.8 & 1.3 & 7 & 51 & 100.1 & 2.0 & 547 & 1.3 \\
\hline
\end{tabular}

${ }^{a} T_{\mathrm{u}}$ : apparent temperature of unfolding at a scan rate of $90 \mathrm{~K} \mathrm{~h}^{-1}$, obtained as described in the Materials and Methods. ${ }^{b} \Delta T_{\mathrm{u}}$ : difference between apparent temperature of unfolding of mutant and that of wild type at a scan rate of $90 \mathrm{~K} \mathrm{~h}^{-1} .{ }^{c} k_{\mathrm{u}}, \Delta G_{\mathrm{u}}{ }^{\ddagger}$ : kinetic constant of unfolding and activation free energy of unfolding, both at $74.5^{\circ} \mathrm{C}$, calculated from $\Delta H_{\mathrm{u}}{ }^{\ddagger}$ and $\Delta S_{\mathrm{u}}{ }^{\ddagger}$, as described in the Materials and Methods. ${ }^{d} k_{\mathrm{u}}$ : kinetic constant of unfolding at $74.5^{\circ} \mathrm{C}$, as a percentage of that of wild type. ${ }^{e} \Delta \Delta G_{\mathrm{u}}{ }^{\ddagger}$ : difference between the activation free energy of unfolding of mutant at $74.5^{\circ} \mathrm{C}$ and that of wild type. ${ }^{f} \Delta H_{\mathrm{u}^{\ddagger}}, \Delta S_{\mathrm{u}}{ }^{\ddagger}$ : activation enthalpy and activation entropy of unfolding at $74.5^{\circ} \mathrm{C}$, obtained as described in the Materials and Methods.

Table 4: Effects of Different Types of Mutations on the Catalytic and Kinetic Unfolding Parameters of Site 263 Mutants of $R$. rubrum Rubisco

\begin{tabular}{|c|c|c|c|c|c|c|c|}
\hline type of change & substitution & mutant 1 & mutant 2 & $\begin{array}{c}k_{\mathrm{cat}}(2) / k_{\mathrm{cat}}(1)^{a} \\
(\%)\end{array}$ & $\begin{array}{l}\Delta \Delta G_{\mathrm{cat}^{\ddagger}}{ }^{-1} \\
\left(\mathrm{~kJ} \mathrm{~mol}^{-1}\right)\end{array}$ & $\begin{array}{c}k_{\mathrm{u}}(2) / k_{\mathrm{u}}(1)^{c} \\
(\%)\end{array}$ & $\begin{array}{c}\Delta \Delta G_{\mathrm{u}}^{\ddagger d} \\
\left(\mathrm{~kJ} \mathrm{~mol}^{-1}\right)\end{array}$ \\
\hline impairment of catalytic role & $\mathrm{D} \rightarrow \mathrm{N}$ & D263 (w-t) & D263N & 13 & 5.05 & 40 & -2.62 \\
\hline $\begin{array}{l}\text { (removal of negatively charged } \\
\text { carboxylate group and reduced potential } \\
\text { for essential electrostatic } \\
\text { interaction with } \mathrm{H} 287 \text { ) }\end{array}$ & $\mathrm{E} \rightarrow \mathrm{Q}$ & D263E & D263Q & 21 & 3.85 & 152 & 1.20 \\
\hline change in structural role & $\mathrm{N} \rightarrow \mathrm{A}$ & $\mathrm{D} 263 \mathrm{~N}$ & D263A & 99 & 0.02 & 125 & 0.65 \\
\hline impairment of both structural and & $\mathrm{D} \rightarrow \mathrm{A}$ & D263 (w-t) & D263A & 13 & 5.07 & 51 & -1.97 \\
\hline catalytic roles & $\mathrm{D} \rightarrow \mathrm{S}$ & D263 (w-t) & D263S & 7 & 6.49 & 38 & -2.82 \\
\hline impairment of catalytic role & $\mathrm{D} \rightarrow \mathrm{E}$ & D263 (w-t) & D263E & 15 & 4.71 & 62 & -1.39 \\
\hline $\begin{array}{l}\text { (insertion of } \mathrm{CH}_{2}-\text { group strains local } \\
\text { structure inhibiting transition-state } \\
\text { formation) }\end{array}$ & $\mathrm{N} \rightarrow \mathrm{Q}$ & $\mathrm{D} 263 \mathrm{~N}$ & D263Q & 24 & 3.51 & 232 & 2.44 \\
\hline
\end{tabular}

abstracts a proton from water to activate it and thus becomes protonated (neutral) (42). It will be apparent that D263 is perfectly placed to modulate the properties of both these active-site residues over the reaction course.

Effect of Creation of an Internal Cavity at Residue 263. Both the $\mathrm{N} \rightarrow \mathrm{A}$ and $\mathrm{N} \rightarrow \mathrm{S}$ substitutions replace a large uncharged side chain by a small one. This can be expected to disrupt any structural role of this side chain (including any $\mathrm{H}$ bond with E194-O, as suggested by the short distance; see Figure 1) and also to create a sizable internal cavity. However, the results in Table 4 show only minor reductions in the catalytic activity of 0.02 and $1.44 \mathrm{~kJ} \mathrm{~mol}^{-1}$, respectively, considerably less than the $\sim 6 \mathrm{~kJ} \mathrm{~mol}^{-1}$ which could be expected from removal of an internal $\mathrm{H}$ bond or structural destabilization from cavity formation itself $(37,39)$. This result indicates that the activation free energy of the transition state of the (rate-limiting) catalytic step is not dependent on the general stability of the localized structure around site 263 .

It is interesting that the introduction of a sizable internal cavity in this region has only a small effect on catalysis but that the opposite type of structural change, i.e., the insertion of a $-\mathrm{CH}_{2}-$ group, has a considerably larger effect. This points to a strong dependence on the specific details of the structural interactions in this region. In the preceding section, we suggested that the results for insertion of a $-\mathrm{CH}_{2}-$ group could be explained by structural distortion induced by the extra group "expanding" into an adjoining region in a way that inhibits transition-state formation. We interpret our results for the cavity-forming substituting mutations as indicating that although the cavity significantly distorts the immediate structural region it does not induce further structural distortion in the adjoining region in a way that would inhibit transition-state formation beyond the impairment already produced by the $\mathrm{D} \rightarrow \mathrm{N}$ mutation.

Effects of Residue 263 Side-Chain Substituents on Binding of Activating (Carbamylating) $\mathrm{CO}_{2}$. The nature of the side chain at site 263 has a considerable effect on the strength of binding of the activating (carbamylating) $\mathrm{CO}_{2}$ molecule to K191. As reflected by the binding constant, $K_{\mathrm{C}}$, binding of $\mathrm{CO}_{2}$ to the two proteins with negatively charged carboxylate groups (wild-type D263 and D263E mutant) is an order of magnitude weaker than the binding to two proteins with large or small uncharged groups at the 263 position (mutants D263N and D263S) (Table 1). These differences in binding strength correspond to differences in the binding free energies, $\Delta \Delta G_{\mathrm{C}}$, of approximately $10 \mathrm{~kJ} \mathrm{~mol}^{-1}$ (Table 1).

We note that our $K_{\mathrm{C}}$ value for wild-type $R$. rubrum Rubisco (7.4 mM, Table 1) is 10 times higher than the value previously reported $(0.6 \mathrm{mM}(35))$. The difference may be due to the different protocols used. The previous value was obtained after the preincubated Rubisco was injected into a solution containing ${ }^{14} \mathrm{C}$-labeled sodium bicarbonate and then quenched after $30 \mathrm{~s}$ (35), whereas our value, as described in the Materials and Methods, was obtained by injecting preincubated Rubisco into assay buffer containing NADH and coupling enzymes and measuring the initial slope of the time course of the optical absorbance at $340 \mathrm{~nm}$. 
These results are consistent with the carboxylate group of wild-type D263 being ionized, rather than protonated (uncharged) as suggested by Duff (13), as the $\mathrm{D} \rightarrow \mathrm{E}$ substitution, which retains the carboxylate group but likely induces localized structural distortion by insertion of the $-\mathrm{CH}_{2}-$ group into the side chain, results in essentially no change to the free energy of carbamylation $\left(\Delta \Delta G_{\mathrm{C}}\right.$ of 0.07 $\mathrm{kJ} \mathrm{mol}^{-1}$, Table 1 ), whereas the $\mathrm{D} \rightarrow \mathrm{N}$ substitution results in a large difference $\left(\Delta \Delta G_{\mathrm{C}}\right.$ of $\left.-9.1 \mathrm{~kJ} \mathrm{~mol}^{-1}\right)$. The presence of a negatively charged carboxylate group at the 263 site is, thus, the critical factor for the binding strength of carbamylation.

A likely explanation for this large effect is that the electrostatic interaction between the negative charge on D263 and the positive charge on the protonated $\varepsilon$-amino group of K191 increases the $\mathrm{p} K_{\mathrm{a}}$ of $\mathrm{K} 191$. It is known that the nonhydrated $\mathrm{CO}_{2}$ molecule, rather than the negatively charged hydrated $\mathrm{HCO}_{3}{ }^{-}$(bicarbonate) ion, is the activating species, and that $\mathrm{CO}_{2}$ must form a carbamate with the nonprotonated (neutral) form of K201 of spinach Rubisco (which corresponds to K191 in the R. rubrum sequence (43)) for activation to occur (44). The value of $K_{\mathrm{C}}$ decreases markedly as the $\mathrm{pH}$ increases from 7.0 to 9.3 , reflecting the increased fraction of neutral Lys $\varepsilon$-amino groups (44). The low $K_{\mathrm{C}}$ values for the mutants $\mathrm{D} 263 \mathrm{~N}$ and D263S with uncharged side chains can be interpreted as due to a decrease in the effective $\mathrm{p} K_{\mathrm{a}}$ of $\mathrm{K} 191$, so that the proportion of neutral $\mathrm{K} 191$ available to react with $\mathrm{CO}_{2}$ at the measurement $\mathrm{pH}$ of 8 is higher.

Effects of D263N Substitution on Binding of Activating $\mathrm{Mg}^{2+}$ Ion. Given the patterns for mutant $K_{\mathrm{C}}$ values for carbamylation just discussed, it is interesting that the values of the binding constant of the activating $\mathrm{Mg}^{2+}$ ion, $K_{\mathrm{Mg}}$, to wild-type D263 and mutant D263N proteins differ only by a factor of 2 (Table 1), indicating only a small effect from a charged side chain. Analogous effects have been reported for the $\mathrm{pH}$ dependence: raising the $\mathrm{pH}$ has a minimal effect on the binding of $\mathrm{Mg}^{2+}$ to spinach Rubisco (43). As shown in Figure 1A,B, the distances between the OD1 carboxyl oxygen of D263 and the NZ atom of K191 or the bound $\mathrm{Mg}^{2+}$ ion in $R$. rubrum (PDB 9RUB) and spinach (PDB 8RUC) Rubisco structures are, respectively, 7.1 and $7.9 \AA$ and 6.8 and $8.0 \AA$; i.e., they are similar. For reference, the OD1 to NZ distance in the structure for nonactivated $R$. rubrum Rubisco (PDB 5RUB) is comparable (8.2 $\AA$ ). The most likely explanation for the apparently large difference in the strengths of the two interactions, as reflected in the dependence of the $K_{\mathrm{C}}$ and $K_{\mathrm{Mg}}$ values on the charge of the 263 residue, is that the charge on $\mathrm{Mg}^{2+}$ is more shielded by the local structure of the surrounding protein, particularly its coordinating ligands.

Effects of Structural Change at Site 263 on Heat-Induced Unfolding. In contrast to the effects on catalytic activity, the effects of different types of structural change at the 263 site on the activation free energy of unfolding, $\Delta \Delta G_{\mathrm{u}}{ }^{+}$, do not appear to be additive (Table 4). Substitutions which remove the negatively charged carboxylate group $(\mathrm{D} \rightarrow \mathrm{N}$ and $\mathrm{E} \rightarrow$ Q) have opposite effects on $\Delta \Delta G_{\mathrm{u}}{ }^{\ddagger}$, as do those which insert the $-\mathrm{CH}_{2}-$ group (D $\rightarrow \mathrm{E}$ and $\mathrm{N} \rightarrow \mathrm{Q}$ ). Substitutions of a large uncharged side chain by a small one $(\mathrm{N} \rightarrow \mathrm{A}$ and $\mathrm{N}$ $\rightarrow \mathrm{S}$ ), thus presumably creating an internal cavity, also have opposite effects on $\Delta \Delta G_{\mathrm{u}}{ }^{\ddagger}$. However, all these effects are minor and do not appear to have obvious significance.
The small kinetic stabilization of Rubisco by the site 263 substitutions shown by the values for $k_{\mathrm{u}}$ (and $T_{\mathrm{u}}$ ) in Table 3 suggests that the rate-limiting (activated) step of unfolding does not involve extensive unfolding of the structure in the region of site 263; otherwise, the substitutions would be expected to be very destabilizing. The reason that these substitutions actually slightly increase the kinetic stability of $R$. rubrum Rubisco is not clear. It is noteworthy that both the $\mathrm{D} \rightarrow \mathrm{A}$ and $\mathrm{D} \rightarrow \mathrm{S}$ substitutions, which replace the large negatively charged wild-type side chain by small uncharged side chains, and thus presumably introduce large internal cavities, actually increase the kinetic stability of the protein molecule by $2-3 \mathrm{~kJ} \mathrm{~mol}^{-1}$ (Table 3 ), whereas, as noted previously, the creation of such an internal cavity could be expected to result in structural destabilization of $6-12 \mathrm{~kJ}$ $\mathrm{mol}^{-1}$ (39). We, therefore, conclude that although the wildtype D263 residue provides critical interactions, particularly with H287, which are necessary for the enhancement of catalysis, it provides less stabilization to the structure of the activated state for unfolding than the alternative residues of the mutants.

However, the rate-limiting (activated) step of heat-induced unfolding does apparently involve substantial structural unfolding because the activation enthalpy of kinetic unfolding, $\Delta H_{\mathrm{u}}{ }^{\ddagger}\left(570 \mathrm{~kJ} \mathrm{~mol}^{-1}\right)$, is $45 \%$ of the overall calorimetric enthalpy, $\Delta H_{\text {cal }}$, of unfolding of the monomer $(1269 \mathrm{~kJ}$ $\mathrm{mol}^{-1}$ ) and $22 \%$ of that of the dimer (Table 2). It is thus reasonable to conclude that this step involves substantial unfolding of the structure in other parts of the protein molecule.

\section{CONCLUSIONS}

Our mutagenesis study of the invariant aspartate residue close to the active site of Rubisco (D263 in R. rubrum) is the first to probe its possible functional and structural roles. We have demonstrated that this residue is essential for maintaining catalytic activity, with mutants showing impairments of $85-97 \%$. Values of $K_{\mathrm{M}}$ for RuBP and substrate $\mathrm{CO}_{2}$ show reductions for all substitutions, very roughly in the same order as the catalytic rates are affected. The effect on the carboxylase/oxygenase specificity, $S_{\mathrm{C} / \mathrm{O}}$, is relatively small $(<10 \%)$, indicating that the mutations affect the kinetic efficiency of the oxygenase and carboxylase reactions similarly.

The presence of the carboxylate group is critical, contributing an average of $4.5 \mathrm{~kJ} \mathrm{~mol}^{-1}$ to $\Delta \Delta G_{\mathrm{cat}}{ }^{\ddagger}(\mathrm{D} \rightarrow \mathrm{N}$ and $\mathrm{E}$ $\rightarrow$ Q substitutions), an effect we attribute mostly to a functional interaction between D163 and H287, which is likely to be only partially or fully ionic depending on the stage of the reaction, and mediated by a water molecule. Insertion of a $-\mathrm{CH}_{2}-$ group into the side chain at site 263 $(\mathrm{D} \rightarrow \mathrm{E}$ and $\mathrm{N} \rightarrow \mathrm{Q}$ substitutions) has a similar effect on catalytic activity, contributing an average of $4.1 \mathrm{~kJ} \mathrm{~mol}^{-1}$ to $\Delta \Delta G_{\text {cat }}{ }^{\ddagger}$. We interpret this as due to strain in a localized region of structure essential for promotion of the transition state of the rate-limiting catalytic step. These effects are additive, such that a value for $\Delta \Delta G_{\mathrm{cat}}{ }^{\ddagger}$ of $8.6 \mathrm{~kJ} \mathrm{~mol}^{-1}$ can be deduced for the $\mathrm{D} \rightarrow \mathrm{Q}$ substitution. The most likely mechanism for both types of mutational change is via $\mathrm{H} 287$ or E194. Consideration of the X-ray structures indicates that D263 is perfectly placed to modulate the properties of both 
these active-site residues over the reaction course, and our recent computational simulations (42) suggest specific roles in several reaction steps (H287) or the hydration step (E194). On the other hand, although substitutions which replace a large uncharged side chain by a small one $(\mathrm{N} \rightarrow \mathrm{A}$ and $\mathrm{N}$ $\rightarrow$ S) can be expected to disrupt any structural role of the side chain and also create a sizable internal cavity, the results show only minor reductions in the catalytic activity (average $\Delta \Delta G_{\text {cat }}{ }^{\ddagger}$ of $0.78 \mathrm{~kJ} \mathrm{~mol}^{-1}$ ). We interpret this as indicating that catalysis is not dependent on the general stability of the localized structure around site 263.

Strikingly, the nature of the side-chain substituent affects the binding constant, $K_{\mathrm{C}}$, of the activating (carbamylating) $\mathrm{CO}_{2}$ molecule greatly but that for the activating $\mathrm{Mg}^{2+}$ ion, $K_{\mathrm{Mg}}$, by only a factor of 2 . Binding of $\mathrm{CO}_{2}$ to proteins with negatively charged carboxylate groups (wild-type D263 and $\mathrm{D} 263 \mathrm{E}$ mutant) is an order of magnitude weaker than the binding to proteins with large or small uncharged groups (mutants $\mathrm{D} 263 \mathrm{~N}$ and $\mathrm{D} 263 \mathrm{~S}$ ), corresponding to a $\Delta \Delta G_{\mathrm{C}}$ value of $\sim 10 \mathrm{~kJ} \mathrm{~mol}^{-1}$. The most likely explanation for this large effect is that the electrostatic interaction between the negative charge on the D263 carboxylate group and the positive charge on the protonated $\varepsilon$-amino group of K191 increases the $\mathrm{p} K_{\mathrm{a}}$ of $\mathrm{K} 191$. On the other hand, we interpret the small variation in $K_{\mathrm{Mg}}$ values as reflecting greater shielding of the positive charge on $\mathrm{Mg}^{2+}$ by the local structure of the surrounding protein, particularly its coordinating ligands, as the distances between D263 and K191, and between D263 and $\mathrm{Mg}^{2+}$, are comparable (7-8 $\AA$ ).

The calorimetry results indicate that the heat-induced unfolding of $R$. rubrum Rubisco is completely irreversible, and thus that the unfolding transition is an entirely kinetic process. The DSC scans suggest that all mutant Rubiscos exist as folded conformations similar to that of the wild type. All substitutions reduce the kinetic rate for unfolding, $k_{\mathrm{u}}$, of Rubisco, i.e., stabilize the protein, but only by a small amount, suggesting that the rate-limiting (activated) step of unfolding does not involve extensive unfolding of the structure in the region of site 263 . Thus, although the catalytic results show that the wild-type D263 residue provides critical interactions, particularly with $\mathrm{H} 287$, which are necessary for the enhancement of catalysis, it provides less stabilization to the structure of the activated state for unfolding than the alternative residues of the mutants. The calorimetry results do, however, show that the rate-limiting (activated) step of heat-induced unfolding involves substantial structural unfolding because the activation enthalpy of kinetic unfolding, $\Delta H_{\mathrm{u}}{ }^{\ddagger}$ $\left(570 \mathrm{~kJ} \mathrm{~mol}^{-1}\right)$, is $45 \%$ of the overall calorimetric enthalpy, $\Delta H_{\text {cal }}$, of unfolding of the monomer $\left(1269 \mathrm{~kJ} \mathrm{~mol}^{-1}\right)$ and $22 \%$ of that of the dimer. But we conclude that this step involves substantial unfolding of the structure in other parts of the protein molecule.

In summary, our study has clarified many aspects of the role of the invariant D263 residue in $R$. rubrum and its equivalent in green plants. Its conservation can thus be accounted for by its contribution to maintenance of a finely tuned structure in this region abutting the active site which is essential for catalysis.

\section{ACKNOWLEDGMENT}

We acknowledge the use of the differential scanning calorimeter purchased from ARC LIEF Grant LE0560751 to N. E. Dixon et al. We acknowledge the ACRF Biomolecular Resources Facility at the John Curtin School of Medical Research, Australian National University for sequencing of vectors. We thank Dr. Minsoo Yoon and Dr. Heather Kane for technical assistance; Professor T. John Andrews and Dr. Dennis McNevin for useful discussions; and Dr. Babu Kannappan, Dr. Spencer Whitney, Dr. Heather Kane and Dr. Denis McNevin for advice on the manuscript.

\section{SUPPORTING INFORMATION AVAILABLE}

An Appendix with details of the determination of the rate of unfolding and the activation parameters of unfolding. This material is available free of charge via the Internet at http:// pubs.acs.org.

\section{REFERENCES}

1. Cleland, W. W., Andrews, T. J., Gutteridge, S., Hartman, F. C., and Lorimer, G. H. (1998) Mechanism of Rubisco: the carbamate as general base. Chem. Rev. 98, 549-561.

2. Spreitzer, R. J., and Salvucci, M. E. (2002) RUBISCO: structure, regulatory interactions, and possibilities for a better enzyme. Annu. Rev. Plant Biol. 53, 449-475.

3. Parry, M. A. J., Andralojc, P. J., Mitchell, R. A. C., Madgwick, P. J., and Keys, A. J. (2003) Manipulation of Rubisco: the amount, activity, function and regulation. J. Exp. Bot. 54, 1321-1333.

4. Andersson, I., and Backlund, A. (2008) Structure and function of Rubisco. Plant Physiol. Biochem. 46, 275-291.

5. Tabita, F. R., Hanson, T. E., Satagopan, S., Witte, B. H., and Kreek, N. E. (2008) Phylogenetic and evolutionary relationships of RubisCO and the RubisCO-like proteins and the functional lessons provided by diverse molecular forms. Philos. Trans. R. Soc. London, Ser. B 363, 2629-2640.

6. Ellis, R. J. (1979) The most abundant protein in the world. Trends Biochem. Sci. 4, 241-244.

7. Kane, H. J., Viil, J., Entsch, B., Kalanethee, P., Morell, M. K., and Andrews, T. J. (1994) An improved method for measuring the $\mathrm{CO}_{2} / \mathrm{O}_{2}$ specificity of ribulosebisphosphate carboxylase-oxygenase. Aust. J. Plant Phvsiol. 21, 449-461.

8. Andrews, T. J., and Whitney, S. M. (2003) Manipulating ribulose bisphosphate carboxylase/oxygenase in the chloroplasts of higher plants. Arch. Biochem. Biophvs. 414, 159-169.

9. Zhu, X. G., Portis, A. R., and Long, S. P. (2004) Would transformation of $\mathrm{C}_{3}$ crop plants with foreign Rubisco increase productivity? A computational analysis extrapolating from kinetic properties to canopy photosynthesis. Plant Cell Environ. 27, 155165.

10. Raines, C. A. (2006) Transgenic approaches to manipulate the environmental responses of the $\mathrm{C} 3$ carbon fixation cycle. Plant Cell Environ. 29, 331-339.

11. Newman, J., and Gutteridge, S. (1993) The X-ray structure of Synechococcus ribulose-bisphosphate carboxylase/oxygenaseactivated quaternary complex at $2.2 \AA$ resolution. J. Biol. Chem. 268, 25876-25886.

12. Andersson, I. (1996) Large structures at high resolution: the $1.6 \AA$ crystal structure of spinach ribulose-1,5-bisphosphate carboxylase/ oxygenase complexed with 2-carboxyarabinitol bisphosphate. $\underline{J}$ Mol. Biol. 259, 160-174.

13. Duff, A. P. (1999) Crystallographic Studies of Rubisco: New Perspectives on Closure and Catalysis in this Two-State Metalloenzyme, Ph.D. Thesis, University of New South Wales, Sydney, Australia.

14. Lundqvist, T., and Schneider, G. (1991) Crystal structure of the ternary complex of ribulose-1,5-bisphosphate carboxylase, $\mathrm{Mg}(\mathrm{II})$, and activator $\mathrm{CO}_{2}$ at 2.3- $\AA$ resolution. Biochemistry 30, 904-908.

15. Lundqvist, T., and Schneider, G. (1991) Crystal structure of activated ribulose-1,5-bisphosphate carboxylase complexed with its substrate, ribulose-1,5-bisphosphate. J. Biol. Chem. 266, 1260412611.

16. Mizohata, E., Matsumura, H., Okano, Y., Kumei, M., Takuma, V, Onodera, V, Kato, K., Shibata, V., Inoue, T., Yokota, V., and Kai, Y. (2002) Crystal structure of activated ribulose-1,5-bisphosphate carboxylase/oxygenase from green alga Chlamydomonas reinhardtii 
complexed with 2 carboxyarabinitol-1,5-bisphosphate. J. Mol. Biol. 316, 679-691.

17. Schneider, G., Lindqvist, Y., and Lundqvist, T. (1990) Crystallographic refinement and structure of ribulose-1,5-bisphosphate carboxylase from Rhodospirillum rubrum at $1.7 \AA$ resolution. $\underline{J}$. Mol. Biol. 211, 989-1008.

18. Suh, S. W., Cascio, D., Chapman, M. S., and Eisenberg, D. (1987) A crystal form of ribulose-1,5-bisphosphate carboxylase/oxygenase from Nicotiana tabacum in the activated state. J. Mol. Biol. 197, 363-365.

19. Taylor, T. C., and Andersson, I. (1997) The structure of the complex between Rubisco and its natural substrate ribulose 1,5-bisphosphate. J. Mol. Biol. 265, 432-444.

20. Frank, J., Vater, J., and Holzwarth, J. F. (1998) Thermodynamics and kinetics of sugar phosphate binding to D-ribulose 1,5bisphosphate carboxylase/oxygenase (RUBISCO). J. Chem. Soc.. Faradav Trans. 94, 2127-2133.

21. Frank, J., Kositza, M. J., Vater, J., and Holzwarth, J. F. (2000) Microcalorimetric determination of the reaction enthalpy changes associated with the carboxylase and oxygenase reactions catalysed by ribulose 1,5-bisphosphate carboxylase/oxygenase (RUBISCO). Phys. Chem. Chem. Phys. 2, 1301-1304.

22. Grinberg, V. Ya., Burova, T. V., Haertlé, T., and Tolstoguzov, V. B. (2000) Interpretation of DSC data on protein denaturation complicated by kinetic and irreversible effects. J. Biotechnol. 79, 269-280.

23. Li, G., Mao, H., Ruan, X., Xu, Q., Gong, Y., Zhang, X., and Zhao, N. (2002) Association of heat-induced conformational change with activity loss of Rubisco. Biochem. Biophvs. Res. Commun. 290, 1128-1132.

24. Whitney, S. M., and Andrews, T. J. (2001) Plastome-encoded bacterial ribulose-1,5-bisphosphate carboxylase/oxygenase (RubisCO) supports photosynthesis and growth in tobacco. Proc. Natl. Acad. Sci. U.S.A. 98, 14738-14743.

25. Studier, F. W. (2005) Protein production by auto-induction in high density shaking cultures. Protein Expression Purif. 41, 207-234.

26. Schloss, J. V., Phares, E. F., Long, M. V., Norton, I. L., Stringer, C. D., and Hartman, F. C. (1982) Ribulose-bisphosphate carboxylase/oxygenase from Rhodospirillum rubrum. Methods Enzymol. 90, 522-528.

27. Lilley, R., and Walker, D. A. (1974) An improved spectrophotometric assay for ribulose- bisphosphate carboxylase. Biochim. Biophys. Acta 358, 226-22.

28. Emlyn-Jones, D., Woodger, F. J., Andrews, T. J., Price, G. D., and Whitney, S. M. (2006) A Synechococcus PCC7942 DccmM (cyanophyceae) mutant pseudoreverts to air growth without regaining carboxysomes. J. Phycol. 42, 769-777.

29. Kane, H. J., Wilkin, J. M., Portis, A. R., and Andrews, T. J. (1998) Potent inhibition of ribulose-bisphosphate carboxylase by an oxidized impurity in ribulose-1,5-bisphosphate. Plant Phvsiol. 117, 1059-1069.
30. Ruuska, S., Andrews, T. J., Badger, M. R., Hudson, G. S., Laisk, A., Price, G. D., and von Caemmerer, S. (1998) The interplay between limiting processes in $\mathrm{C}_{3}$ photosynthesis studied by rapidresponse gas exchange using transgenic tobacco impaired in photosynthesis. Aust. J. Plant Phvsiol. 25, 859-870.

31. McNevin, D., von Caemmerer, S., and Farquhar, G. (2006) Determining RuBisCO activation kinetics and other rate and equilibrium constants by simultaneous multiple non-linear regression of a kinetic model. J. Exp. Bot. 57, 3883-3900.

32. Privalov, P. L., and Potekhin, S. A. (1986) Scanning microcalorimetry in studying temperature-induced changes in proteins. Methods Enzymol. 131, 24-51.

33. Zamyatnin, A. A. (1972) Protein volume in solution. Prog. Biophvs. Mol. Biol. 24, 107-123.

34. Fersht, A. (1985) Enzyme Structure and Mechanism, 2nd ed., W. H. Freeman and Company, New York.

35. Christeller, J. T., and Laing, W. A. (1978) A study of ribulose bisphosphate carboxylase from the photosynthetic bacterium Rhodospirillum rubrum. Biochem. J. 173, 467-473.

36. Makhatadze, G. I., and Privalov, P. L. (1995) Energetics of protein structure. Adv. Protein Chem. 47, 307-425.

37. Myers, J. K., and Pace, C. N. (1996) Hydrogen bonding stabilizes globular proteins. Biophvs. J. 71, 2033-2039.

38. Olson, C. A, Spek, E. J., Shi, Z., Vologodskii, A., and Kallenbach, N. R. (2001) Cooperative helix stabilization by complex Arg-Glu salt bridges. Proteins: Struct. Funct. Genet. 44, 123-132.

39. Eriksson, A. E., Baase, W. A., Zhang, X.-J., Heinz, D. W., Blaber, M., Baldwin, E. P., and Matthews, B. W. (1992) Response of a protein structure to cavity-creating mutations and its relation to the hydrophobic effect. Science 255, 178-183.

40. Liggins, J. R., Lo, T. P., Brayer, G. D., and Nall, B. T. (1999) Thermal stability of hydrophobic heme pocket variants of oxidized cytochrome c. Protein Sci. 8, 2645-2654.

41. Andersson, I., and Taylor, T. C. (2003) Structural framework for catalysis and regulation in ribulose-1,5-bisphosphate carboxylase/ oxygenase. Arch. Biochem. Biophys. 414, 130-140.

42. Kannappan, B., and Gready, J. E. (2008) Redefinition of the Rubisco carboxylase reaction reveals origin of water for hydration and new roles for active-site residues. J. Am. Chem. Soc. 130, 15063-15080.

43. Lorimer, G. H., Badger, M. R., and Andrews, T. J. (1976) The activation of ribulose-1,5-bisphosphate carboxylase by carbon dioxide and magnesium ions. Equilibria, kinetics, a suggested mechanism, and physiological implications. Biochemistry 15, 529536.

44. Laing, W. A., and Christeller, J. T. (1976) A model for the kinetics of activation and catalysis of ribulose 1,5-bisphosphate carboxylase. Biochem. J. 159, 563-570.

BI802159E 